\title{
Impact of Courageous Followership towards Promoting Exemplary Leadership
}

\author{
* Dr. Muhammad Zia-ur-Rehman, Associate Professor (Corresponding Author) \\ ** Dr. Waseem Ishaque, Assistant Professor \\ *** Rimsha Zafar, Researcher
}

\begin{abstract}
The current study focuses not only on developing leadership but also emphasizes the crucial role of employing the concept of followership effectively. The reason for this is that the leadership concept in the organization may not be effective without followership. Therefore, to obtain exemplary leadership, followership has to be inculcated, and that of courage embedded in it. The current study applied to reverse the lens approach in leadership and hypothesized the relation between courageous followership and exemplary leadership. The sample size of 255 was used for this research, chosen by employing convenience-sampling techniques due to Covid-19 conditions and restrictions. The data were screened and then using SPSS did analysis. The results show that courageous followership had an impact on exemplary leadership, meaning that courageous followers would promote exemplary leadership practices in the organizations, which can be very useful for organizations to understand and promote.
\end{abstract}

\section{Keywords: Courageous Followership, Exemplary Leadership Practices}

\section{Introduction}

In today's competitive world, the follower role became as important as the leadership role. Colangelo (2000) explains that followers should work as a co-partner to their leaders by taking charge of their responsibilities and the followers should know that they are a huge part of the organization's success. Chaleff (2009) describes that courageous followers can lead the organization towards success by helping their leaders and taking responsibility for their work. Kouzes \& Posner (2002) described in the leadership practices that these leaders have the best personal life experiences. Exemplary leaders always adopt ethical and moral principles and when followers are courageous they are more likely to stand against any immoral activity (Chaleff, 2009). The research of Bryant (2017) also concluded that people who practiced exemplary leadership are more satisfied, committed, and powerful leaders.

In Pakistan, the main focus is on leadership development whereas the main focus should be on follower development. The people have become obsessed with their leader as they expect that leader is the only one responsible for everything but they forget that behind every leader's success, there is always a follower. Every individual wants to become a leader no one wants to become a follower whereas every single person, even a leader act as a follower in his life. According to the Pakistan Institute of Management, the institute has trained more than 250000 managers since 1954, but there is no focus on developing the followership skills, which are necessary to be a great leader. Therefore, in today's dynamic environment, followership is a very crucial part and we need to focus on developing courageous followership skills in individuals. There were few empirical studies found on courageous followership. According to Shehzadi, John, Qadeer, \& Mehnaz (2017), there is also a lack of studies of followership in Pakistan's context. Carsten, Uhl-Bien, West, Patera, and McGregor's (2010) theory says that the followers behave passively and don't bother to ask about queries, and obeying leaders blindly can cause trouble. As explained by Colangelo (2000) that leaders may achieve goals and get awards but there is a hand of follower behind the success as the followers gives the best solutions at worst situations. According to Baker et al., (2011), courageous followers see themselves as a partner to leader and help those making effective followers. This study signifies that there is a

* Department of Leadership and Management Studies, National Defense University

Email: drziaofficial@gmail.com

** Department of IR, NUML Email: Waseemishaque@yahoo.com

*** Department of Leadership and Management Studies, National Defence University

Email: 
relation between courageous followership and exemplary leadership, which means that courageous followers do promote exemplary leadership in the organization.

\section{Research Question}

Does Courageous followership promotes exemplary leadership?

\section{Hypothesis}

There is a significant and positive contribution of Courageous Followership towards Promoting Exemplary Leadership

\section{Literature Review}

\section{Courageous Followership}

According to Dixon \& Westbrook (2003), courageous followership describes by a person who demonstrates numerous behaviors. Chaleff (2009) describes those behaviors as the dimensions of courageous followers, which include the courage to assume responsibility, courage to challenge, the courage to serve, courage to take moral actions, and courage to participate in transformation. According to Kelley (2008), some ways can help a person to become successful which includes instructing and educating people about followership role that role involves courageous conscience, also give enough support to followers so they can exercise their courageous conscience and helping followers so they can find the courage to stand up for themselves.

Ricketson (2008) explained that the followers who are not afraid to serve their leader and they know about the hard work needed, are the courageous followers. Those followers self-assume their responsibility and they think that it is their responsibility to unburden the leader and serve for their organization. The study done by Rolle (2018) proposed that if the courageous follower wants, they can take decisions and proposed a new system for organization. According to the study of Ghias, Hassan, \& Masood (2018), courageous followership helps in the development of exemplary leadership. Courageous followers influence and contribute to moral values, as they do not follow blindly. Employee's proactive behaviors can be acknowledged, utilized, and rewarded by existing leaders so the followers can make great future leaders.

Baker \& Stites-doe (2011) courageous followership facilitates the followers to see themselves as partners to leader and help those making effective followers. These types of followers dare to serve in the organization. True leadership is the combination of leading and following because the individuals who lead they had followed somehow someone (Tsakeni \& Jita, 2017). The study done by Shehzadi et al. (2017) discourages the followers who act like passive followers and encourages the proactive follower who can help and trust their leaders and help them to make the right decisions.

Warton II (2016) also study moral courage which is one of the dimensions of (Chaleff, 2009) followership behaviors which can be associate with the requirement to take courage to challenge the leaders to benefit the organization and creating an environment of trust to run a successful organization. Bjugstad Thach, Thompson, \& Morris (2006) identified that the leaders become more effective when they understand the relation of leader and follower, moreover, the followers who are more committed to their work would result in great leaders in the future. Whereas, Ghias et al. (2018) suggested that the courageous followership helps the followers to see their leader as a partner, by doing so they can be more effective for their organization, and by adapting exemplary leadership practices, they can become a great leader in the future.

\section{Exemplary Leadership}

Kouzes \& Posner (2013) explain different Exemplary leadership practices that can be adapted by leaders, which include; model the way, inspired the shared vision, enable others to act, challenge the process and encourage the heart. Herrera (2017) defined exemplary leadership as the person who is different from others by having such characteristics which include; a person who had good relationships with their followers, a person who is successfully running and leading the organization, or a person whom people recognize, etc. There should be exemplary programs in universities so that students can adopt these practices in their life (Young \& Eddy-Spicer, 2019).

Kouzes \& Posner (2002) described in the leadership practices that these leaders have the best personal life experiences. Exemplary leaders always adopt ethical and moral principles. Exemplary leaders always have a clear vision and they are forward thinkers but they must communicate to followers their vision regarding organizations (Young \& Eddy-Spicer, 2019). The study of Zagorsek, Jaklie, and Strough (2004) showed the comparison between three different countries in which these 
exemplary leadership practices were implemented to see the result of culture impact on leadership behaviors.

Exemplary leadership quality is likely to develop in followers who help the leaders and adapt to change easily; the exemplary leaders not only bring the change but also adapt change in them along with their followers (Hage \& Posner, 2015). Moniz (2008) studies show that the exemplary leadership practices and the mentoring shares a relation and it should be practice on the development of woman in organizations whereas the exemplary leadership practices would also help and encourage students to be a great leader in future (Posner, 2012).

According to Uranga (2009), that the leaders who adopt exemplary leadership practice, for instance, enable others to act, cannot achieve the organizational goals alone, they need their followers to cooperate with leaders. Bryant (2017) concluded in his study that organizations or educational institutes should provide professors, administration the exemplary leadership practice, and the collection of 360 feedback would help the leader to understand its followers. The study of Díaz, Sánchez-Vélez, and Santana-Serrano (2019) stated that entrepreneurial education must adapt Exemplary leadership practices to develop policies based on results. The research of Bryant (2017) also concluded that people who practiced exemplary leadership are more satisfied, committed, and powerful leaders.

\section{Theoretical Framework}

\section{Exemplary Leadership and Courageous Followership}

The researcher used leader-member exchange theory to study courageous followership and Exemplary leadership. The leader-member exchange theory has suggested that there is a dyadic relationship between leader and follower that results in the quality of leadership effectiveness and their quality is determined by cooperation between leader and follower (Graen \& Uhl-bien, 1995). For this research, the leader-member exchange theory has been reversed, the focus of this approach is how followership behavior identifies the leadership behavior and its outcome, further this approach studies the leadership styles as followership outcomes (Uhl-Bien, Riggio, Lowe, \& Carsten, 2014).

Uhl-Bien et al., (2014) categorized followership into two categories: first, the relation-based approach is based on the interaction of followers with leaders, and second, the role-based approach is "how followers influence their leader's behavior". For this study, the role-based approach has been followed. Several studies investigated the link between leadership and followership (Bjugstad et al., 2006; Chou, 2012; Ghias et al., 2018; Van Vugt et al., 2008). The proactive behavior of subordinates can be acknowledged, utilized, and rewarded by existing leaders, this will help in making the followers great future leaders (Ghias et al., 2018). Johnson (2009) studied that introducing the followership and follower's role at the institute level would lead students towards the development of a leader in the organization. Kouzes and Posner (2013) describe the five exemplary leadership practices along with ten commitments, which are needed to be a great leader. These practices adapted by courageous followers would enhance the relationship between leader and courageous follower.

The study of Carsten, Uhl-Bien, West, Patera, \& McGregor (2010) states that the employee who have courageous followership behavior and plays a role as a follower can exhibit a leadership role in the future. The courageous followers do not follow the leaders blindly instead they show courage and stand against unethical behavior. To be ethical, it needs moral courage and trustworthiness and these qualities are need in exemplary leadership practices (Hage \& Posner, 2015). Chaleff (2009) describes that the courageous followers challenge the decisions of leader whenever needed and this also leads towards exemplary leadership as the exemplary leadership does not wait for change to happen instead they bring the change and also contribute followers in decisions (Hage \& Posner, 2015).

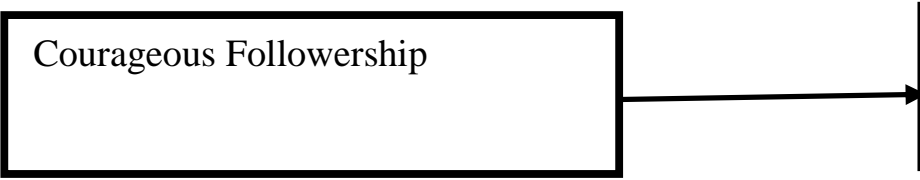

Exemplary Leadership

Figure 1: Conceptual Framework of the study

\section{Methodology}

Research methodology is used to identify and analyze information about a certain topic. Research methodology is used to ensure the validity and reliability of data to design a study. The purpose of 
research methodology is to design it by using different techniques. Researcher methodology provides comprehensive findings. This chapter discusses the methods adopted for this research study. This chapter explores the research design and research procedure. Further, this chapter focuses on the scope of the study. It also considers the data analysis technique used to answer the questions of this research.

\section{Population}

According to Bougie and Sekaran (2016), the population includes the entire group of individuals or procedures, the researcher desires to explore. The population of this research is conducted and consisted of university students among twin cities. To collect the authentic numbers, the data will be collected from Rawalpindi/ Islamabad organizations where no such research has been carried before. As many people recently graduated from different universities and would be introduced to the industry so it would be interesting to know about those individuals' courageous followership and exemplary leadership practices.

\section{Sample}

A sample is the subset of the population as it contains some of the members from the population. There are two types of sampling techniques, which can be used to collect data. One is called probability sampling and the other is called non-probability sampling. The researcher opted for nonprobability sampling. The sampling technique, which is used for this research study, was nonprobability convenience sampling where data was collected from those participants who were conveniently available to provide it. This technique is used because the data can be collected easily, and quickly. The research should be held on the entire population but it is impossible to do that because the population is very large, that's why the easiest way to gather data is by using convenience sampling technique. The researcher used the convenience-sampling technique because of the lack and shortage of time and resources. A sample size of 255 was used for this research. The participants were taken from the twin cities i.e. Rawalpindi and Islamabad.

The questionnaire was developed by Dixon (2003) under the supervision of (Chaleff, 2009) based on the courageous followership behavior. The scale consisted of 16 items. The measuring of responses was held by using 5 point Likert scale which ranges from strongly disagree to strongly agree. This questionnaire was also used in different researches. The questionnaire would help participants to evaluate their courageous behavior as a follower.

Kouzes developed the exemplary leadership questionnaire \& Posner (2007) consisted of 10 items. The measuring of responses was held by using 5 point Likert scale which ranges from strongly disagree to strongly agree.

\section{Data screening}

Data screening should be done before any statistical procedure. The assumption of regression is used in which the histogram and scatter plot represent the normality of data. The data was analyzed by using SPSS 21.

\section{Data collection method}

The process of collecting data and measuring data for research purposes is known as the data collection method. The researcher can assess the hypothesis with the help of collected data. Using different ways and different resources can collect data. Data can be collected by primary or secondary data. Primary data is the data, which is collected by the researcher for the specific purpose of the study. Primary data collection methods include interviews, observation, questionnaires, and experiments. Secondary data can be gathered through different existing sources and other people collect it for other purposes and it can be used for the current study.

This research is descriptive and the best way to collect data was the questionnaire method.

\section{Response rate}

A total of 320 questionnaires were distributed in numbers but only 255 responses were found able for this research because 29 questionnaires had missing values and 36 did not respond to the questionnaire, therefore only 255 responses were considered appropriate for this research. The response rate was almost $80 \%$.

\section{Results}

The demographic statistics of participants are given below. Total 255 participants participated in this survey. 
Table 1:Demographics of the Study $(n=255)$

\begin{tabular}{lll}
\hline Demographics & Frequency & Percentage \\
\hline Gender & & \\
Male & 85 & 34 \\
Female & 170 & 66 \\
Experience (in years) & & \\
$0-2$ & 176 & 69 \\
$3-5$ & 71 & 28 \\
$6-10$ & 8 & 3 \\
Age & & 70 \\
$20-25$ & 180 & 20 \\
$26-30$ & 51 & 10 \\
$31-35$ & 24 & 64 \\
Qualification & & 31 \\
Undergraduate & 163 & 5 \\
Graduate & 79 & \\
Masters & 13 & \\
\hline
\end{tabular}

Table 1 shows the demographic details of participants along with frequency and percentage. The participants consist of 85 males and 170 females who filled this survey with the percentage of $34 \%$ and $66 \%$ respectively. $69 \%$ of the participant had $0-2$ years of experience, $28 \%$ were having 3-5 years of experience, and only 3\% were participants who had 6-10 years of experience. However, 70\% belongs to the age group of 20-25, $20 \%$ belongs to the $26-30$, and $10 \%$ of the participants belonged to the age group of 30-35. Among the participants, $64 \%$ were undergraduate, $31 \%$ were graduate, and only $5 \%$ had qualifications of masters' level.

Descriptive Statistics

Table 2: Descriptive Statistics of the Study $(n=255)$

\begin{tabular}{lll}
\hline Variables & Mean & S.D \\
\hline CF & 3.7 & .60 \\
EL & 3.5 & .59 \\
\hline
\end{tabular}

Table 2 shows descriptive statistics in which it shows the mean and standard deviation of the variables. Courageous Followership had a mean value of 3.7 whereas exemplary leadership had a mean value of 3.5 , which clearly shows that respondents had clearly understood the statement agree with statements.

\section{Reliability}

According to Sekaran and Bougie (2016), reliability is used to measure the stability and consistency of the items. To check the reliability, Cronbach's Alpha $(\alpha)$ is used. The reliability is acceptable if it is 0.7 (out of 1). A value greater than .9 is considered as excellent as, greater than .8 is good, whereas .7 is acceptable (Gliem \& Gliem, 2003). The reliability of the instruments is given below.

Table 3: Reliability of all instruments $(n=255)$

\begin{tabular}{lll}
\hline Instrument & $\mathrm{N}$ of item & Cronbach's Alpha \\
\hline Courageous Followership & 16 & .89 \\
Exemplary Leadership & 10 & .83 \\
\hline
\end{tabular}

The total number of items in courageous followership was 16 and its Cronbach Alpha value was $.89(\alpha=.89)$ and the number of items in exemplary leadership was $10(\alpha=.83)$, which means that data was consistent.

\section{Correlation}

The value of correlation lies between -1 to 1 . If the value exceeds 1 or below -1 then this means that correlational values are inaccurate. The technique used to measure the relationships among variables was Pearson Correlation. The table below shows the correlation of variables.

Table 4: Correlation of Variables $(n=255)$

\begin{tabular}{lll}
\hline Variables & I & II \\
\hline I-Organizational Climate & - & .128 \\
II-Exemplary Leadership & .128 & - \\
\hline$* *$ Correlation is significant at the 0.05 level (2-tailed). Source: SPSS & \\
The results clearly show that there are significant relationships among variables. There is positive and \\
significant relation between courageous followership and exemplary leadership (r=. 128, $\mathrm{p}<.05)$.
\end{tabular}




\section{Regression}

To test the hypothesis, regression analysis was used to examine the relation between independent and dependent variables i.e. courageous followership and Exemplary Leadership.

Table 5: Regression Analysis $(n=255)$

\begin{tabular}{|c|c|c|c|c|c|}
\hline \multirow[t]{2}{*}{ Model } & \multirow[t]{2}{*}{$\mathrm{R}$} & \multirow[t]{2}{*}{ R Square } & \multirow[t]{2}{*}{ B } & \multicolumn{2}{|l|}{ Change Statistics } \\
\hline & & & & R Square Change & Sig. F Change \\
\hline 1 & $.128^{\mathrm{a}}$ & .016 & .128 & .016 & .04 \\
\hline
\end{tabular}

To test the impact of courageous followership on exemplary leadership practices, multiple regression analysis was used as shown in the table above. The results show significant change on exemplary leadership, $\mathrm{R}^{2}=.016, \mathrm{p}<0.05$. The results indicate that courageous followership contributes towards exemplary leadership that means that if a person is a courageous follower then he would become an exemplary leader in the future. This study is in line with previous studies done by (Ghias et al., 2018; Tsakeni \& Jeti, 2017; Schwab, 2017). These findings prove that a person having both qualities of leader and follower would be showing true leadership act.

\section{Discussion}

The individuals who are courageous follower would help their leaders to become more exemplary leaders and they would show honesty towards their organization, would enable other to act, and by involving employees in decision making by inspiring the shared vision. Those employees would become more efficient and effective future leaders. Lemoine et al. (2019) suggested in their study that the leader can inspire followers by their moral and ethical freedom and the followers are motivated to contribute to this system if lead by a true leader. If the focus of courageous followership is shifted towards the individuals then this would help them to become a great leader themselves and also it would delete the toxic leaders from our culture (Ghias et al., 2018).

Furthermore, Carsten et al. (2010) states that the employees who have courageous followership behavior and play a role as a follower can exhibit a leadership role in the future. Courageous followership. The individual who adapts and practices courageous followership behavior would become a great leader in the future because he would be the one who would stand against any unethical behavior, will take challenges, and would serve the organization with honesty and accountability.

\section{Recommendations for future research}

Followership can be explored in detail, as there are not many studies done on courageous followership. There was always discussion about leadership but now the focus should be turned to followership development. Following the qualitative approach as it might get different results can do the study. The components of the variables should be discussed in further studies. Followership development is necessary because this would increase the chance of individuals to become great leaders in the future. The sample size was limited because the present study was conducted in this pandemic situation. In Pakistan, there are very few researches about the courageous followership approach as it is a new concept in the research.

\section{Conclusion}

Back then organizations only focus on developing the leadership role whereas there was little or no knowledge regarding the importance of followership role. Followers are the backbone of the organization. The leader is nothing without its followers. In a developing country like Pakistan, there is a need for courageous followers in the organization so that there are fewer passive followers and less negativity in the organization. Courageous followers serve their leader with full integrity and change according to the organization. They do not blindly follow the leader and speak against any unethical activity. There is a need for courageous followers in Pakistan because their ability to take responsibility and accountability would lead the organization towards success.

\section{References}

Baker, S. D., Mathis, C. J., \& Stites-doe, S., (2011). An Exploratory Study Investigating Leader and Follower Characteristics at U . S. Healthcare Organizations. Managerial Issues, 23(3), 341363.

Bjugstad, K., Thach, E. C., Thompson, K. J., \& Morris, A. (2006). A Fresh Look at Followership: a model for matching followership and leadership styles. Institute of Behavioral and Applied Management, (2002), 304-320. 
Bryant, R. (2017). Teacher Leader Behaviors: A Quantitative Study of a Teacher Leadership Development Academy and Teacher Leaders' Five Practices of Exemplary Leadership Behaviors (Doctoral dissertation, University of La Verne).

Carsten, M. K., Uhl-Bien, M., West, B. J., Patera, J. L., \& McGregor, R. (2010). Exploring social constructions of followership: A qualitative study. Leadership Quarterly, 21(3), 543-562.

Chaleff, I. (2009). The courageous follower: Standing up to \& for our leaders. Berrett-Koehler Publishers.

Chou, S. Y. (2012). Millennials in the Workplace: A Conceptual Analysis of Millennials' Leadership and Followership Styles. International Journal of Human Resource Studies, 2(2), 71. Retrieved from https://doi.org/10.5296/ijhrs.v2i2.1568

Colangelo, A. J. (2000). Followership: Leadership styles (Doctoral dissertation).

Díaz, E. R., Sánchez-Vélez, C. G., \& Santana-Serrano, L. (2019). Integrating the Five Practices of the Exemplary Leadership Model into Entrepreneurship Education. International Journal for the Scholarship of Teaching and Learning, 13(3), 10.

Dixon, G., \& Westbrook, J. (2003). Followers revealed. EMJ - Engineering Management Journal.

Ghias, W., Hassan, S., \& Masood, T. M. (2018). Does Courageous Followership contribute to exemplary Leadership Practices: Evidence from Pakistan? International Journal of Business \& Management, 13(June), 11-22.

Gliem, J. A., \& Gliem, R. R. (2003). Calculating, interpreting, and reporting Cronbach's Alpha Reliability Coefficient for Likert-type Scales. Studies in Inorganic Chemistry, 82-88.

Graen, G. B. (1976). Role-making processes within complex organizations. Handbook of industrial and organizational psychology.

Graen, G. B., \& Uhl-Bien, M. (1995). Relationship-based approach to leadership: Development of leader-member exchange (LMX) theory of leadership over 25 years: Applying a multi-level multi-domain perspective.

Hage, J., \& Posner, B. Z. (2015). Religion, religiosity, and leadership practices. Leadership \& Organization Development Journal.

Herrera, S. A. (2017). Exemplary leadership: A mixed-methods case study discovering how female chief executive officers create meaning.

Johnson, C. E. (2009). Introducing Followership into the Leadership Classroom. Journal of Leadership Education, 8(2), 20-31.

Uranga, M. A. (2009). Exemplary leadership practices, exploring culture preferences. Our Lady of the Lake University.

Kelley, R. E. (2008). Rethinking followership.

Kouzes, J. M., \& Posner, B. Z. (2013). The Five Practices of Exemplary Leadership-Asia. John Wiley $\&$ Sons.

Lemoine, G. J., Hartnell, C. A., \& Leroy, H. (2019). Taking stock of moral approaches to leadership: An integrative review of ethical, authentic, and servant leadership. Academy of Management Annals, 13(1), 148-187.

Moniz, D. C. (2008). Leadership development: The relationship between successful mentoring relationships and exemplary leadership practices among women protégés within the United States Navy (Doctoral dissertation, Capella University).

Posner, B. Z. (2012). Effectively measuring student leadership. Administrative Sciences, 2(4), 221234.

Ricketson, S. (2008). An exploration of the relationship of leadership styles and dimensions of courageous followership. Doctoral Thesis.

Rolle, S. R. (2018). Operant Conditioning Theory and Courageous Followership. Theology of Leadership Journal, 1(2), 48-63.

Shahzadi, G., John, A., Qadeer, F., \& Mehnaz, S. (2017). Followership behavior and leaders' trust: Do political skills matter? Pakistan Journal of Commerce and Social Sciences, 11(2), 653670.

Schwab, K. W. (2017). Teaching and Learning Courageous Followership: An Action Research Study. Theses \& Dissertations. 
Tsakeni, M., \& Jita, L. C. (2017). Followership and sustainability of school leadership for Science and Mathematics: A distributive perspective. Journal of Education (University of KwaZuluNatal), (69), 237-256.

Uhl-Bien, M., Riggio, R. ., Lowe, K. ., \& Carsten, M. (2014). Followership theory: A review and research agenda. The Leadership Quarterly, 25(1), 83-14.

Van Vugt, M., Hogan, R., \& Kaiser, R. B. (2008). Leadership, Followership, and Evolution: Some Lessons From the Past. American Psychologist, 63(3), 182-196.

Warton II, G. B. (2016). Steward followership measurement. ProQuest Dissertations and Theses, 9(2).

Young, M. D., \& Eddy-Spicer, D. H. (2019). Bridging, Brokering, Bricolage: Building exemplary leadership programs from the inside out.

Zagorsek, H., Jaklic, M., \& Stough, S. J. (2004). Comparing leadership practices between the United States, Nigeria, and Slovenia: does culture matter? Cross-Cultural Management: An International Journal. 